Article

\title{
Penostatin Derivatives, a Novel Kind of Protein Phosphatase 1B Inhibitors Isolated from Solid Cultures of the Entomogenous Fungus Isaria tenuipes
}

\author{
Yu-Peng Chen ${ }^{1,2}$, Chun-Gui Yang ${ }^{1,2}$, Pei-Yao Wei ${ }^{1,2}$, Lin Li ${ }^{1,2}$, Du-Qiang Luo ${ }^{1,2, *}$, \\ Zhi-Hui Zheng ${ }^{3}$ and Xin-Hua Lu ${ }^{3}$
}

1 College of Life Science, Key Laboratory of Medicinal Chemistry and Molecular Diagnosis of Ministry of Education, Hebei University, Baoding 071002, China

2 Biotechnology Center of Hebei Province, Hebei University, Baoding 071002, China

3 New Drug Research and Development Center, North China Pharmaceutical Group Corporation, Shijiazhuang 051007, China

* Author to whom correspondence should be addressed; E-Mail: duqiangluo@163.com;

Tel./Fax: +86-0312-507-9364.

Received: 20 December 2013; in revised form: 22 January 2014 / Accepted: 23 January 2014 / Published: 29 January 2014

\begin{abstract}
Protein tyrosine phosphatase 1B (PTP1B) is implicated as a negative regulator of insulin receptor (IR) signaling and a potential drug target for the treatment of type II diabetes and other associated metabolic syndromes. Therefore, small molecular inhibitors of PTP1B can be considered as an attractive approach for the design of new therapeutic agents of type II diabetes diseases. In a continuing search for new protein phosphatase inhibitors from fungi, we have isolated a new compound, named penostatin $\mathrm{J}(\mathbf{1})$, together with three known ones, penostatin C (2), penostatin A (3), and penostatin B (4), from cultures of the entomogenous fungus Isaria tenuipes. The structure of penostatin J (1) was elucidated by extensive spectroscopic analysis. We also demonstrate for the first time that penostatin derivatives exhibit the best PTP1B inhibitory action. These findings suggest that penostatin derivatives are a potential novel kind of PTP1B inhibitors.
\end{abstract}

Keywords: Isaria tenuipes; penostatin derivatives; protein phosphatase 1B inhibitor 


\section{Introduction}

Tyrosine phosphorylation and dephosphorylation are crucial elements in eukaryotic signal transduction [1]. Phosphatases can be subdivided into the protein tyrosine phosphatase (PTP) and protein serine/threonine phosphatase (PSP) classes [2]. The PTP superfamily are divided into more than three families: (i) 'classical PTPs', which exist both as transmembrane forms (such as LAR or PTP-a) and non-transmembrane forms (such as PTP1B or TC-PTP); (ii) the dual-specificity phosphatases, which are able to dephosphorylate both phosphotyrosine and phosphothreonine in specific sequence contexts; (iii) the low molecular weight phosphotyrosine protein phosphatases (LMW-PTPs) [3,4]. More recent evidence has suggested PTP1B as a major negative regulator of the insulin signaling pathway [5,6]. As so far, several 'classical' PTP are attractive therapeutic targets, including PTP1B for obesity and type II diabetes; SHP2 for cancer and Lyp for rheumatoid arthritis [6]. Although the research efforts were made in academia and industry over the past decade, there are very few PTPase inhibitors that have been advanced into clinical trials [7]. Thus, inhibitors of PTP1B can also be considered as an attractive approach for the design of new therapeutic agents for the treatment of type II diabetes and new antitumoral drugs. To date very few inhibitors have isolated from microorganisms, particularly insect pathogenic fungi [8]. Therefore, insect pathogenic fungi have been considered as an untapped source of small molecules PTP inhibitors.

Insect pathogenic fungi are an ecologically highly specialized group of microorganisms. Some 700 entomopathogenic species are presently known, belonging to the families of Deuteromycetes, Ascomycetes, Zygomycetes, Oomycetes, Chytridiomycetes, Trichomycetes and Basidiomycetes [8]. Insect pathogenic fungi produce a plethora of insecticidally and pharmaceutically active compounds. For example, the cyclic depsipeptides destruxins [9], beauvericin, bassianolides, the beauveriolides [10] and lactams, such as pyridovericin [11] have been reported from some Deuteromycetes. Especially at 2010, fingolimod (Gilenya, FTY720), a synthetic compound based on the insect fungal secondary metabolite myriocin (ISP-I) [12], is a potent immunosuppressant that was approved (September 2010) by the U.S. FDA as a new treatment for multiple sclerosis (MS) [13]. Therefore, interest in searching for bioactive compounds from insect pathogenic fungi has increased considerably recently $[14,15]$. China has been proven to be a rich source of insect pathogenic fungi [16], this prompted us to undertake further phytochemical investigation. In a continuing search for new PTP1B inhibitors from insect pathogenic fungi, we have isolated a new compound, named penostatin $\mathrm{J}(\mathbf{1})$, together with the known ones penostatin C (2), penostatin A (3), and penostatin B (4) (Figure 1) from cultures of the entomogenous fungi Isaria tenuipes. Details of the isolation and structural elucidation of $\mathbf{1}$ are reported herein.

Figure 1. The structures of compounds 1-4.

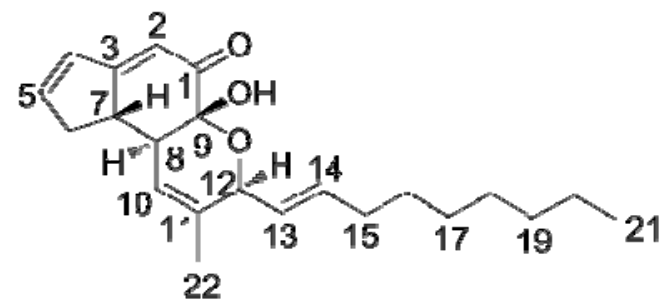

1

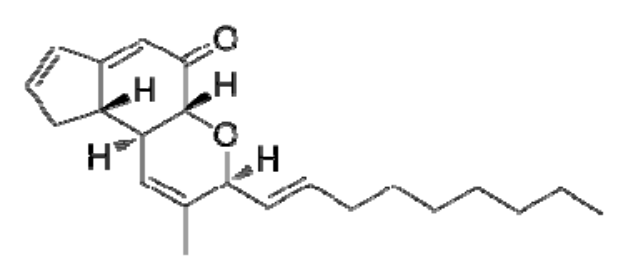

2 
Figure 1. Cont.

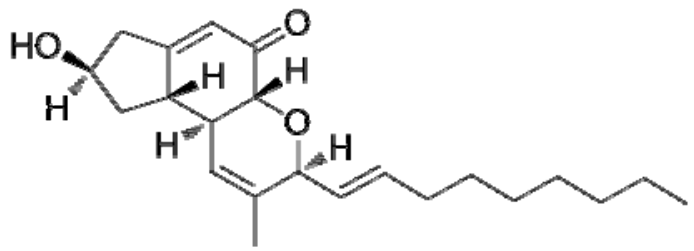

3

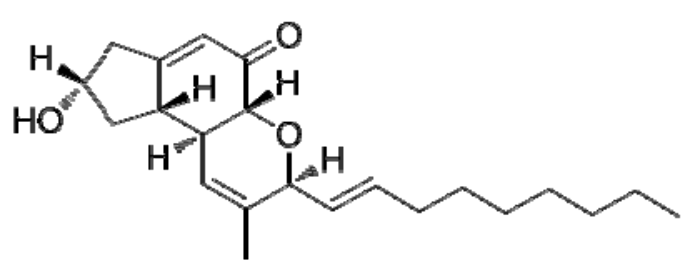

4

\section{Results and Discussion}

Compound 1 was obtained as a yellow oil. The HRESI-MS of 1 gave an $[\mathrm{M}+\mathrm{Na}]^{+}$peak at $\mathrm{m} / \mathrm{z}$ 365.20820 (calcd for $\mathrm{C}_{22} \mathrm{H}_{30} \mathrm{NaO}_{3}, 365.20872$ ) and corresponded to a molecular formula of $\mathrm{C}_{22} \mathrm{H}_{30} \mathrm{O}_{3}$, requiring eight degrees of unsaturation. A close inspection of the ${ }^{1} \mathrm{H}$ - and ${ }^{13} \mathrm{C}-\mathrm{NMR}$ data (Table 1) of 1 by DEPT techniques and HMQC revealed the presence of a conjugated ketone at $\delta(\mathrm{C}) 194.7$, two disubstituted double bonds at $\delta(\mathrm{C}) 128.1$ and 135.6, and 131.4 and 150.9, two trisubstituted double bonds (four olefinic carbons at $\delta$ (C) 113.8 and 174.6, and 119.7 and 134.5), an allylic methyl at $\delta(\mathrm{C}) 18.2$, a primary methyl at $\delta(\mathrm{C})$ 12.9, seven methylenes (C6 and $\mathrm{C} 15-\mathrm{C} 20$ ) and three $\mathrm{sp}^{3}$-hybridized methines $(\mathrm{C} 7, \mathrm{C} 8$, and $\mathrm{C} 12)$ including one oxygen-bearing methine. An analysis of the ${ }^{1} \mathrm{H}$ and ${ }^{13} \mathrm{C}$-NMR spectral data (Table 1 ) indicated compound $\mathbf{1}$ was very similar to penostatin $\mathrm{C}$, which suggested that compound 1 possesses the same substitution pattern [17]. The distinct difference between $\mathbf{1}$ and $\mathbf{2}$ are that: the chemical shifts value at C-9 of $\mathbf{1}\left(\delta_{C} 91,9(\mathrm{~s})\right)$ were absent in $\mathbf{2}\left(\delta_{C} 74.9\right.$ (d)) which implied that the hydrogen of C-9 in $\mathbf{2}$ is replaced by hydroxy into a quaternary carbon in $\mathbf{1}$. In the light of the evidences mentioned above and key ${ }^{1} \mathrm{H}-{ }^{1} \mathrm{H}$ COSY and HMBC correlations (Figure 2), the planar structure of $\mathbf{1}$ was thus elucidated as show in Figure 1. The stereochemistry for $\mathbf{1}$ was established by comparison observed coupling constants and NOESY data with penostatins A-D [17]. The relative configuration of C-7, C-8 and C-12 except for C-9 was shown to be the same as that of 2 by the coupling constants of $\mathrm{H}-8$ to $\mathrm{H}-7$, and NOEs from $\mathrm{H}-22$ to $\mathrm{H}-12, \mathrm{H}-13$ and $\mathrm{H}-14$. This was also supported by the measurement of J12,13 $(6.5 \mathrm{~Hz})$ and $\mathrm{J} 13,14(15.5 \mathrm{~Hz})$ coupling constants in 1 which were the same as in $\mathbf{2}$. The absolute configuration of C-9 was further determined by comparing the circular dichroism (CD) and $[\alpha]_{D}$ spectra with compound 2 (Supporting Information). The positive Cotton effect at $201 \mathrm{~nm}$ in the CD spectrum of 1 indicated the $9 R$ configuration, supporting the abovementioned absolute stereostructure for 1. In addition, the Cotton effect at $289 \mathrm{~nm}$, which is considered to correspond to that at $274 \mathrm{~nm}$ in $\mathbf{2}$, was found as a negative sign as in $\mathbf{2}$. This result supported the 7S configuration of $\mathbf{1}$ [18]. Finally, on the basis of these data, the stereochemistry of 1 was thus determined as shown (Figure 1) and the compound was named penostatin J.

\section{PTP1B Activities}

Compounds 1-4 displayed significant PTP1B inhibitory action with $\mathrm{IC}_{50}$ values from 0.37 to $43.6 \mu \mathrm{M}$ (Table 2). It is important to note that compound $\mathbf{1}$ and $\mathbf{2}$ have exhibited significant selectivity between PTP1B and LAR. LAR exists as a transmembrane form, but LTP1Bs exist as a non-transmembrane forms. To our knowledge, the PTP1B inhibitory action of compounds $\mathbf{1}$ and $\mathbf{2}$ is the same as that of 
ertiprotafib and MSI-1436, two compounds with $\mathrm{IC}_{50}$ values of 1.6 and $1.0 \mu \mathrm{M}$, respectively, whose inhibitory action has been evaluated in vivo (Phase II and I) [19]. This is first time that penostatin derivatives are reported to have significant PTP1B inhibitory action.

Table 1. ${ }^{1} \mathrm{H}$ and ${ }^{13} \mathrm{C}-\mathrm{NMR}$ data for $\mathbf{1}$ and penostatin $\mathrm{C}(\mathbf{2})$.

\begin{tabular}{|c|c|c|c|c|}
\hline \multirow{2}{*}{ Position } & \multicolumn{2}{|l|}{1} & \multicolumn{2}{|l|}{ Penostatin C (2) } \\
\hline & $\delta(\mathbf{H})$ & $\delta(\mathbf{C})$ & $\delta(\mathbf{H})$ & $\delta(\mathbf{C})$ \\
\hline 1 & & 194.7 & & 197.8 \\
\hline 2 & $5.95(\mathrm{~d}, J=2.4 \mathrm{~Hz})$ & 113.8 & $5.87(\mathrm{~d}, J=2.4 \mathrm{~Hz})$ & 115.7 \\
\hline 3 & & 174.6 & & 173.8 \\
\hline 4 & $6.54(\mathrm{dt}, J=5.6 ; 2.3 \mathrm{~Hz})$ & 131.4 & $6.52(\mathrm{dt}, J=5.5 ; 2.4 \mathrm{~Hz})$ & 131.6 \\
\hline 5 & $6.87(\mathrm{dt}, J=5.6 ; 2.3 \mathrm{~Hz})$ & 150.9 & $6.82(\mathrm{dt}, J=5.5 ; 2.3 \mathrm{~Hz})$ & 149.4 \\
\hline \multirow[t]{2}{*}{6} & $2.90(\mathrm{dddd}, J=16.9 ; 5.9 ; 1.5 ; 2.0 \mathrm{~Hz})$ & 36.8 & $2.89(\mathrm{dddd}, J=17.5 ; 6.5 ; 1.5 ; 2.0 \mathrm{~Hz})$ & 36.2 \\
\hline & $2.52(\mathrm{dddd}, J=16.9 ; 4.1 ; 1.5 ; 2.0 \mathrm{~Hz})$ & & $2.50($ dddd, $J=17.5 ; 4.2 ; 1.5 ; 2.0 \mathrm{~Hz})$ & \\
\hline 7 & $2.99(\mathrm{dddd}, J=10.8 ; 7 ; 3.7 ; 2.3 \mathrm{~Hz})$ & 46.5 & $2.77(\mathrm{dddd}, J=11.2 ; 6.8 ; 3.6 ; 2.5 \mathrm{~Hz})$ & 45.7 \\
\hline 8 & $2.28(\mathrm{tq}, J=10.8 ; 1.9 \mathrm{~Hz})$ & 44.9 & $2.49(\mathrm{tq}, J=11.4 ; 2.2 \mathrm{~Hz})$ & 44.9 \\
\hline 9 & & 91.9 & $4.44(\mathrm{~d}, J=11.1 \mathrm{~Hz})$ & 74.9 \\
\hline 10 & $5.76(\mathrm{~m})$ & 119.7 & $5.67(\mathrm{~m})$ & 115.7 \\
\hline 11 & & 134.5 & & 135.9 \\
\hline 12 & $4.67(\mathrm{~d}, J=6.5 \mathrm{~Hz})$ & 76.2 & $4.57(\mathrm{~d}, J=6.4 \mathrm{~Hz})$ & 77.7 \\
\hline 13 & $5.37(\mathrm{dd}, J=6.5 ; 15.5 \mathrm{~Hz})$ & 128.1 & $5.62(\mathrm{dd}, J=6.6 ; 15.5 \mathrm{~Hz})$ & 126.3 \\
\hline 14 & $5.79(\mathrm{dd}, J=15.5,6.5 \mathrm{~Hz})$ & 135.6 & $5.74(\mathrm{dt}, J=15.5 ; 6.9 \mathrm{~Hz})$ & 136.2 \\
\hline 15 & $2.08(\mathrm{~m})$ & 31.8 & $2.09(\mathrm{~m})$ & 31.8 \\
\hline 16 & $1.42(\mathrm{~m})$ & 28.7 & $1.31(\mathrm{~m})$ & 28.6 \\
\hline 17 & 1.31 (brs) & 28.8 & 1.28 (brs) & 28.7 \\
\hline 18 & 1.31 (brs) & 28.7 & 1.28 (brs) & 28.6 \\
\hline 19 & 1.31 (brs) & 31.6 & 1.28 (brs) & 31.6 \\
\hline 20 & 1.31 (brs) & 22.3 & 1.28 (brs) & 22.3 \\
\hline 21 & $0.91(\mathrm{t}, J=6.8 \mathrm{~Hz})$ & 12.9 & $0.88(\mathrm{t}, J=6.8 \mathrm{~Hz})$ & 13.0 \\
\hline 22 & $1.65(\mathrm{~s})$ & 18.2 & $1.59(\mathrm{~s})$ & 18.7 \\
\hline
\end{tabular}

Note: 1 and 2 were measured in $\mathrm{CDCl}_{3}$. Assignments made on the basis of ${ }^{1} \mathrm{H},{ }^{1} \mathrm{H}-\mathrm{COSY}, \mathrm{HMQC}$ and HMBC experiments.

Figure 2. The ${ }^{1} \mathrm{H}-{ }^{1} \mathrm{H}-\mathrm{COSY}$, selected key HMBC correlations of $\mathbf{1}$.

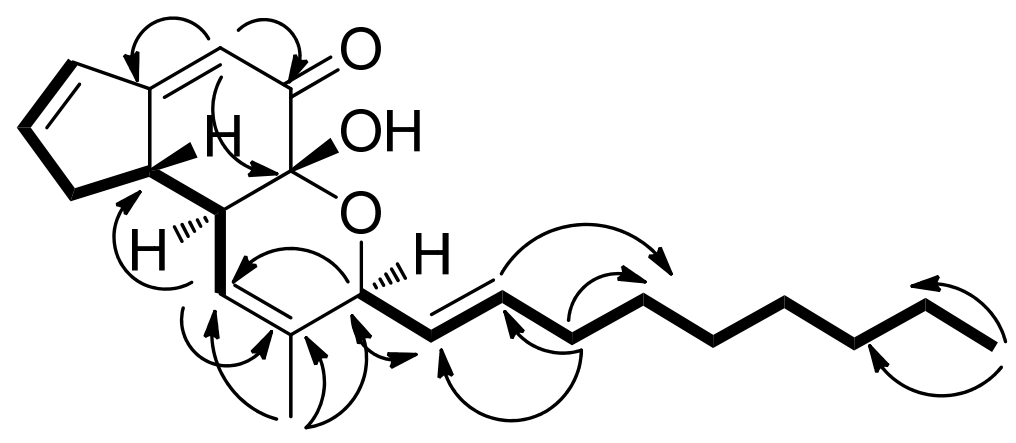


Table 2. Potency and selectivity of penostatin derivatives PTP1B inhibitors.

\begin{tabular}{ccc}
\hline \multirow{2}{*}{ Compound } & \multicolumn{2}{c}{$\mathbf{I C}_{\mathbf{5 0}}(\boldsymbol{\mu M})$} \\
\cline { 2 - 3 } & PTP1B & LAR $^{\mathbf{a}}$ \\
\hline $\mathbf{1}$ & $12.53 \pm 0.9$ & $\mathrm{a}$ \\
$\mathbf{3}$ & $0.37 \pm 0.05$ & $53.33 \pm 4.06$ \\
$\mathbf{4}$ & $15.87 \pm 2.49$ & $\mathrm{a}$ \\
Sodium orthovanadate & $33.65 \pm 7.33$ & $\mathrm{a}$ \\
(positive control) & $0.65 \pm 0.08$ & $0.89 \pm 0.02$ \\
\hline
\end{tabular}

Note: ${ }^{a}$ represents no inhibition at $50 \mu \mathrm{g} / \mathrm{mL}$. The data were expressed as mean $\pm \mathrm{SD}$ of three replicates.

\section{Experimental}

\subsection{General}

Optical rotations were obtained on a Perkin-Elmer 341 spectropolarimeter. UV Spectra were recorded on a UV-210 spectrometer. IR spectra were recorded on a Perkin-Elmer 577 spectrometer. The ${ }^{1} \mathrm{H}$ - and ${ }^{13} \mathrm{C}-\mathrm{NMR}$ spectra were recorded on a Bruker AM-600 spectrometer at 600 and $150.9 \mathrm{MHz}$ using TMS as internal standard. HRESIMS data were measured on a Bruker FT-ICR-MS mass spectrometer. TLC was carried out using glass-precoated silica gel $\mathrm{GF}_{254}$ (Yantai Zhi Fu Chemical Co., Ltd, Yantai, China) and visualized under UV light or by spraying with vanilin (contains $\mathrm{H}_{2} \mathrm{SO}_{4}$ ) ethanol reagent. Sephadex LH-20 gel (25 100 $\mu \mathrm{m}$, GE Healthcare Co., Ltd., Uppsala, Sweden), silica gel (200-300 mesh, Yantai Zhi Fu Chemical Co., Ltd) were used for column chromatography (CC).

\subsection{Fungal Material and Cultivation Conditions}

Isaria tenuipes was isolated from an unidentified lepidopteran collected in Hebei Province, China, and identified by Yong-Chun Niu, It has been catalogued as strain RCEF 37776 in the culture collection of the Key Laboratory of Medicinal Chemistry and Molecular Diagnosis of Ministry of Education, Hebei University. The fungal strain was cultured on slants of potato dextrose agar (PDA) at $28{ }^{\circ} \mathrm{C}$ for $7 \mathrm{~d}$, and then inoculated into 500-mL Erlenmeyer flask containing $100 \mathrm{~mL}$ of PDA medium (20.0 g of glucose, $200.0 \mathrm{~g}$ of potato (peeled), $3.0 \mathrm{~g}$ of $\mathrm{KH}_{2} \mathrm{PO}_{4}, 1.5 \mathrm{~g}$ of $\mathrm{MgSO}_{4}, 0.1 \mathrm{~g}$ of citric acid, and $10.0 \mathrm{mg}$ of thiamin hydrochloride, in $1 \mathrm{~L}$ of deionized $\mathrm{H}_{2} \mathrm{O}$ ). The final $\mathrm{pH}$ of the media was adjusted to 6.5 before sterilization. After $7 \mathrm{~d}$ of incubation at $28{ }^{\circ} \mathrm{C}$ on rotary shakers at $150 \mathrm{rpm}$, mycelial pieces were transferred to 50 Erlenmeyer flask $(500 \mathrm{~mL})$ containing $200.0 \mathrm{~g}$ rice medium, ( $88 \mathrm{~g}$ rice, $110 \mathrm{~mL}$ distilled water) and the fermentation was carried out on a incubator for $40 \mathrm{~d}$.

\subsection{Extraction and Isolation}

At the end of the incubation period, the mycelium and medium were extracted with EtOAc $(20 \mathrm{~L})$. The extract was concentrated to dryness and the residue $(87.0 \mathrm{~g})$ was separated on a silica gel column eluted with petroleum ether (PE)/EtOAc (100:0, 98:2, 95:5, 90:10, 60:10, 30:10, 10:10 (v/v)) to afford seven fractions, Frs.1-7. Fr.3 (500 mg) was additionally purified by CC eluted with PE/acetone 50:1 $(v / v)$ and LH-20 (methanol) to afford compound 2 (6 mg; TLC (PE/EtOAc (45:1); $\left.\mathrm{R}_{f}=0.6\right)$. Fr. 6 (3.0 g) 
eluted with PE/EtOAc (30:10) was repeatedly purified by $\mathrm{CC}$ (silica gel; PE/acetone 3:1 (v/v)) and

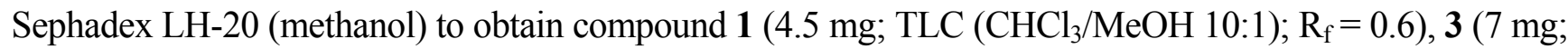
$\left.\mathrm{TLC}\left(\mathrm{CHCl}_{3} / \mathrm{MeOH} 10: 1\right) ; R_{f}=0.5\right)$ and $4\left(8 \mathrm{mg} ; \mathrm{TLC}\left(\mathrm{CHCl}_{3} / \mathrm{MeOH} 10: 1\right) ; R_{f}=0.6\right)$, respectively.

\subsection{Physico-Chemical Properties}

Penostatin $J(1)$ : Isolated as a pale yellow oil, $[\alpha]_{D}^{24}=59.3(\mathrm{c}=0.003, \mathrm{MeOH})$. IR $(\mathrm{KBr}) \mathrm{v}_{\max }: 3442$, 2926, 2854, 1659, $1618 \mathrm{~cm}^{-1}$. UV $\left(\mathrm{CHCl}_{3}\right) \lambda_{\max }(\lg \varepsilon): 289$ (3.45), 203 (3.35) nm. ${ }^{1} \mathrm{H}-$ and ${ }^{13} \mathrm{C}-\mathrm{NMR}$, see Table 1. Positive ion HR-ESI-MS [M+Na] $]^{+} \mathrm{m} / z$ 365.20820 (calcd for $\mathrm{C}_{22} \mathrm{H}_{30} \mathrm{O}_{3} \mathrm{Na}, 365.20872$ ).

Penostatin $C$ (2): Isolated as a yellow oil. $[\alpha]_{D}^{24}=87.5(\mathrm{c}=2.2, \mathrm{MeOH})$. IR $(\mathrm{KBr}) \mathrm{v}_{\max }: 3427,2926$, 2854, 1658, $1618 \mathrm{~cm}^{-1}$. UV $\left(\mathrm{CHCl}_{3}\right) \lambda_{\max }(\lg \varepsilon): 280$ (3.39), 0.3422 (3.54) nm. ${ }^{1} \mathrm{H}-$ and ${ }^{13} \mathrm{C}-\mathrm{NMR}$, see Table 1. Positive ion HR-ESI-MS [M+Na] $]^{+} m / z 349.22453$ (calcd for $\mathrm{C}_{22} \mathrm{H}_{30} \mathrm{O}_{2} \mathrm{Na}, 349.22445$ ). It was identified as penostatin $\mathrm{C}$ by comparison of the spectral data with the literature $[17,18]$.

Penostatin A (3): Isolated as a yellow oil. $[\alpha]_{D}^{24}=+56.8(\mathrm{c}=2.2, \mathrm{MeOH})$. IR $(\mathrm{KBr}) \mathrm{v}_{\max }: 3425,2924$, 2853, 1675, $1633 \mathrm{~cm}^{-1}$. UV $\left(\mathrm{CHCl}_{3}\right) \lambda_{\max }(\lg \varepsilon): 253$ (3.78), $202(3.90) \mathrm{nm} .{ }^{1} \mathrm{H}-\mathrm{NMR}\left(\mathrm{CDCl}_{3}\right) \delta 5.64$ (1H, s, H-2), 2.42 (1H, d, $J=1.74 \mathrm{~Hz}, \mathrm{H}-4 \alpha), 2.98(1 \mathrm{H}, \mathrm{dd}, J=7.5 \mathrm{~Hz}, 18.5, \mathrm{H}-4 \beta), 4.43$ ((1H, m, H-5), $2.53(1 \mathrm{H}, \mathrm{ddd}, J=11.8,7.0,1.9 \mathrm{~Hz}, \mathrm{H}-6 \alpha), 1.50$ (1H, td, $J=12.5,4.8 \mathrm{~Hz}, \mathrm{H}-6 \beta), 2.45$ (1H, m, H-7), $2.53(1 \mathrm{H}, \mathrm{m}, \mathrm{H}-8), 4.08(1 \mathrm{H}, \mathrm{d}, J=11.5 \mathrm{~Hz}, \mathrm{H}-9), 5.92(1 \mathrm{H}, \mathrm{m}, \mathrm{H}-10), 4.55(1 \mathrm{H}, \mathrm{d}, J=6.5 \mathrm{~Hz}, \mathrm{H}-12)$, $5.62(1 \mathrm{H}, \mathrm{dd}, J=13.9,5.6 \mathrm{~Hz}, \mathrm{H}-13), 5.74(1 \mathrm{H}, \mathrm{dt}, J=13.8,6.7 \mathrm{~Hz}, \mathrm{H}-14), 2.12$ (2H, m, H-15), 1.42 (2H, m, H-16), 1.31 (4H, brs, H-17, 18, 19, 20), 0.91 (3H, t, $J=6.8 \mathrm{~Hz}, \mathrm{H}-21), 1.69$ (3H, s, H-22). ${ }^{13} \mathrm{C}-\mathrm{NMR}\left(\mathrm{CDCl}_{3}\right) \delta 197.1(\mathrm{~s}, \mathrm{C}-1), 121.5$ (d, C-2), 172.3 (s, C- 3), 40.9 (t, C-4), 70.2 (d, C-5), 37.8 (t, C-6), 45.4 (d, C-7), 44.9 (d, C-8), 73.7 (d, C-9), 121.2 (d, C-10), 135.9 (s, C-11), 77.5 (d, C-12), 126.3 (d, C-13), 135.8 (d, C-14), 31.8 (t, C-15), 28.7 (t, C-16), 28.7 (t, C-17), 28.7 (t, C-18), 31.6 (t, C-19), 22.3 (t, C-20), 13.0 (q, C-21), 18.7 (q, C-22). Positive ion HR-ESI-MS [M+Na] ${ }^{+} \mathrm{m} / \mathrm{z} 367.23543$ (calcd for $\mathrm{C}_{22} \mathrm{H}_{32} \mathrm{O}_{3} \mathrm{Na}, 367.23514$ ). It was identified as penostatin $\mathrm{A}$ by comparison of the spectral data with the literature $[17,18]$.

Penostatin B (4): Isolated as a yellow oil. $[\alpha]_{D}^{24}=-24.5(\mathrm{c}=2.2, \mathrm{MeOH})$. IR (KBr) $\mathrm{v}_{\max }: 3460,2921$, 1671, 1632, $1466 \mathrm{~cm}^{-1}$. UV $\left(\mathrm{CHCl}_{3}\right) \lambda_{\max }(\lg \varepsilon): 234(3.43), 202(3.45) \mathrm{nm} .{ }^{1} \mathrm{H}-\mathrm{NMR}\left(\mathrm{CDCl}_{3}\right) \delta 5.65$ $(1 \mathrm{H}, \mathrm{s}, \mathrm{H}-2), 2.36(1 \mathrm{H}, \mathrm{t}, J=1.68 \mathrm{~Hz}, \mathrm{H}-4 \alpha), 2.87(1 \mathrm{H}, \mathrm{m}, \mathrm{H}-4 \beta), 4.50(1 \mathrm{H}, \mathrm{m}, \mathrm{H}-5), 2.63(1 \mathrm{H}, \mathrm{d}$, $J=19.8 \mathrm{~Hz}, \mathrm{H}-6 \alpha), 1.57$ (1H, ddd, $J=10.7,9.2,5.9 \mathrm{~Hz}, \mathrm{H}-6 \beta), 2.27$ (1H, m, H-7), 2.85 (1H, m, H-8), $4.14(1 \mathrm{H}, d, J=11.6 \mathrm{~Hz}, \mathrm{H}-9), 5.93(1 \mathrm{H}, \mathrm{m}, \mathrm{H}-10), 4.57(1 \mathrm{H}, \mathrm{d}, J=6.5 \mathrm{~Hz}, \mathrm{H}-12), 5.62(1 \mathrm{H}, \mathrm{dd}$, $J=5.5,6.0 \mathrm{~Hz}, \mathrm{H}-13), 5.74(1 \mathrm{H}, \mathrm{dt}, J=13.8,6.7 \mathrm{~Hz}, \mathrm{H}-14), 2.12(2 \mathrm{H}, \mathrm{m}, \mathrm{H}-15), 1.42$ (2H, m, H-16), 1.31 (4H, brs, H-17, 18, 19, 20), $0.91(3 \mathrm{H}, \mathrm{t}, J=6.8 \mathrm{~Hz}, \mathrm{H}-21), 1.69(3 \mathrm{H}, \mathrm{s}, \mathrm{H}-22) .{ }^{13} \mathrm{C}-\mathrm{NMR}\left(\mathrm{CDCl}_{3}\right)$ $\delta 198.3$ (s, C-1), 122.9 (d, C-2), 174.5 (s, C-3), 42.4 (t, C-4), 71.4 (d, C-5), 39.5 (t, C-6), 46.2 (d, C-7), 46.1 (d, C-8), 75.1 (d, C-9), 122.4 (d, C-10), 137.3 (s, C-11), 78.8 (d, C-12), 127.5 (d, C-13), 137.1 (d, C-14), 33.1 (t, C-15), 29.9 (t, C-16), 29.9 (t, C-17), 30.0 (t, C-18), 32.9 (t, C-19), 23.5 (t, C-20), 14.3 (q, C-21), 19.9 (C-22). Positive ion HR-ESI-MS $[\mathrm{M}+\mathrm{Na}]^{+} \mathrm{m} / z 367.23523$ (calcd for $\mathrm{C}_{22} \mathrm{H}_{32} \mathrm{O}_{3} \mathrm{Na}$, 367.23514). It was identified as penostatin $\mathrm{B}$ by comparison of the spectral data with the literature $[17,18]$. 


\subsection{Biological Evaluation}

PTP1B activity was measured as the rate of hydrolysis of $p$-nitrophenyl phosphate $(p N P P)$ in a 96-well microtiter plate format [20]. Standard assays were conducted at room temperature in a total volume of $0.2 \mathrm{~mL}$ that contained HEPES buffer $(50 \mathrm{mM}, \mathrm{pH} 7.2), \mathrm{NaCl}(50 \mathrm{mM})$, EDTA (1 mM), DTT $(1 \mathrm{mM})$, bovine serum albumin $(1 \mathrm{mg} / \mathrm{mL}), p$ NPP (at various concentrations, Km) $1.4(0.03 \mathrm{mM})$, and PTP1B (35 $\mathrm{ng} / \mathrm{mL})$. Sodium orthovanadate was used as the positive control. Inhibitors were added in DMSO at 100 times the final concentration. PTP1B activity was measured as the rate of inorganic phosphate released upon hydrolysis of the IR phosphopeptide, TRDIpYETDpYpYRK, using a Malachite Green method [21]. The enzyme activity was estimated by measuring the absorbance at $405 \mathrm{~nm}$ with appropriate corrections. Each experiment was performed either in triplicate, and $\mathrm{IC}_{50}$ data were derived from three independent experiments.

Activities of LAR were measured as described above except that the HEPES buffer $(50 \mathrm{mM})$ was at $\mathrm{pH} 6.8$, and the enzyme was added at a concentration of $10 \mu \mathrm{g} / \mathrm{mL}$. Activity of calcineurin (from Sigma Chemical Co.) was assayed using 4-methylumbelliferyl phosphate $(0.8 \mathrm{mM})$ as a substrate in an assay mixture that contained Tris- $\mathrm{HCl}$ buffer $(40 \mathrm{mM}, \mathrm{pH} 8.6), \mathrm{NaCl}(100 \mathrm{mM}), \mathrm{CaCl}_{2}(0.5 \mathrm{mM})$, DTT $(0.5 \mathrm{mM})$, bovine serum albumin $(0.1 \mathrm{mg} / \mathrm{mL})$, calmodulin $(50 \mathrm{nM})$, and calcineurin $(25 \mathrm{nM})$. Sodium orthovanadate was used as the positive control. Fluorescence at $450 \mathrm{~nm}$ was monitored with excitation at $400 \mathrm{~nm}$. The color was allowed to develop at room temperature for $30 \mathrm{~min}$, and the sample absorbances were determined at $650 \mathrm{~nm}$ using a plate reader (Molecular Devices, Sunnyvale, $\mathrm{CA}, \mathrm{USA}$ ). Each experiment was performed either in triplicate, and $\mathrm{IC}_{50}$ data were derived from three independent experiments.

Calculations. PTPase activities, based on a potassium phosphate standard curve, were expressed as nanomoles of phosphate released $/ \mathrm{min} / \mathrm{mg}$ protein. Inhibition of recombinant h-PTP1B by test compounds was calculated as percent of phosphatase control. A four-parameter nonlinear logistic regression of PTPase activities using SAS release 6.08, PROC NLIN, was used for determining IC $_{50}$ values of the test compounds. The reported $\mathrm{IC}_{50}$ values show significant fit to the regression curve $(p<0.05)$.

\section{Conclusions}

On the whole, we have isolated a new compound, named penostatin $\mathrm{J}(\mathbf{1})$, together with three known compounds penostatin C (2), penostatin A (3) and penostatin B (4), from cultures of the entomogenous fungus Isaria tenuipes. We also demonstrate for the first time that penostatin derivatives have the best PTP1B inhibitory action. These findings suggest the penostatin derivatives are a potential novel kind of PTP1B inhibitor.

\section{Supplementary Materials}

Supplementary materials can be accessed at: http://www.mdpi.com/1420-3049/19/2/1663/s1. 


\section{Acknowledgments}

This work was supported by National Natural Science Foundation of China (31171885 and 31371957), Hebei Province Science Fund for Distinguished Young Scholars (C2011201113), the Ph. D. Programs Foundation of Ministry of Education of China (20121301110006), key Projects in the Hebei Province Science \& Technology (13226508D) and support by The Program for Changjiang Scholars and Innovative Research Team in University (IRT1124).

\section{Author Contributions}

Du-Qiang Luo conceived and designed the study. Yu-Peng Chen, Chun-Gui Yang, Pei-Yao Wei and Lin Li performed the isolated and identified experiments. Zhi-Hui Zheng and Xin-Hua Lu performed biological evaluation. Yu-Peng Chen and Du-Qiang Luo wrote the paper. Du-Qiang Luo reviewed and edited the manuscript. All authors read and approved the manuscript.

\section{Conflicts of Interest}

The authors declare no conflict of interest.

\section{References}

1. Hunter, T. Signaling - 2000 and beyond. Cell 2000, 100, 113-127.

2. Manning, G.; Whyte, D.B.; Martinez, R.; Hunter, T.; Sudarsanam, S. The protein kinase complement of the human genome. Science 2002, 298, 1912-1934.

3. Forghieri, M.; Laggner, C.; Paoli, P.; Langer, T.; Manao, G.; Camici, G.; Bondioli, L.; Prati, F.; Costantino, L. Synthesis, activity and molecular modeling of a new series of chromones as low molecular weight protein tyrosine phosphatase inhibitors. Bioorg. Med. Chem. 2009, 17, 2658-2672.

4. Andersen, J.N.; Mortensen, O.H.; Peters, G.H.; Drake, P.G.; Iversen, L.F.; Olsen, O.H.; Jansen, P.G.; Andersen, H.S.; Tonks, N.K.; Moller, N.P. Structural and evolutionary relationships among protein tyrosine phosphatase domains. Mol. Cell. Biol. 2001, 21, 7117-7136.

5. Van Huijsduijnen, R.H.; Sauer, W.H.B.; Bombrun, A.; Swinnen, D. Prospects for inhibitors of protein tyrosine phosphatase 1B as antidiabetic drugs. J. Med. Chem. 2004, 47, 4142-4146.

6. Barr, A.J. Protein tyrosine phosphatases as drug targets: Strategies and challenges of inhibitor development. Future Med. Chem. 2010, 2, 1563-1576.

7. Liu, G. Protein tyrosine phosphatase 1B inhibition: Opportunities and challenges. Curr. Med. Chem. 2003, 10, 1407-1421.

8. Hajek, A.E.; Leger, R.J., St. Interactions between fungal pathogens and insect hosts. Rev. Entomol. 1994, 39, 293-322.

9. Isaka, M.; Kittakoop, P.; Kirtikara, K.; Hywel-Jones, N.L.; Thebtaranonth, Y. Bioactive substances from insect pathogenic fungi. Acc. Chem. Res. 2005, 38, 813-823.

10. Namatame, I.; Tomoda, H.; Tabata, N.; Si, S.; Ōmura, S. Structure elucidation of fungal beauveriolide III, a novel inhibitor of lipid droplet formation in mouse macrophages. J. Antibiot. 1999, 52, 7-12. 
11. Takahashi, S.; Uchida, K.; Kakinuma, N.; Hashimoto, R.; Yanagisawa, T.; Nakagawa, A. The structures of pyridovericin and pyridomacrolidin, new metabolites from the entomopathogenic fungus, Beauveria Bassiana. J. Antibiot. 1998, 51, 1051-1054.

12. Fujita,T.; Inoue, K.; Yamamoto, S.; Ikumoto, T.; Sasaki, S.; Toyama R.; Chiba, K.; Hoshino, Y.; Okumoto, T. Fungal metabolites: Part 11. A potent immunosuppressive activity found in Isaria sinclairii metabolite. J. Antibiot. 1994, 47, 208-215.

13. Strader, C.R.; Pearce, C.J.; Oberlies, N.H. Fingolimod (FTY720): A recently approved multiple sclerosis drug based on a fungal secondary metabolite. J. Nat. Prod. 2011, 74, 900-907.

14. Isaka, M.; Palasarn, S.; Tobwor, P.; Boonruangprapa, T.; Tasanathai, K. Bioactive anthraquinone dimers from the leafhopper pathogenic fungus Torrubiella sp. BCC 28517. J. Antibiot. 2012, 11, 571-574.

15. Isaka, M.; Chinthanom P.; Sappan, M.; Chanthaket, R.; Luangsa-ard, J.J.; Prabpai, S.; Kongsaeree, P. Lanostane and hopane triterpenes from the entomopathogenic fungus Hypocrella sp. BCC 14524. J. Nat. Prod. 2011, 74, 2143-2150.

16. Zhu, J.S.; Halpern, G.M.; Jones, K.J. The scientific rediscovery of an ancient chinese herbal medicine: Cordyceps sinensis: Part I. J. Altern Complement. Med. 1998, 4, 289-303.

17. Takahashi, C.; Numata, A.; Yamada, T.; Minoura, K.; Enomoto, S.; Konishi, K.; Nakai, M.; Matsuda, C.; Nomoto K. Penostatins, novel cytotoxic metabolites from a Penicillium species separated from a green alga. Tetrahedron Lett. 1996, 37, 655-658.

18. Iwamoto, C.; Minoura, K.; Oka, T.; Ohta, T.; Hagishita, S.; Numata, A. Absolute stereostructures of novel cytotoxic metabolites, penostatins A-E, from a Penicillium species separated from an Enteromorpha alga. Tetrahedron 1999, 55, 14353-14368.

19. Scott, L.M.; Lawrence, H.R.; Sebti, S.M.; Lawrence, N.J.; Wu, J. Targeting protein tyrosine phosphatases for anticancer drug discovery. Curr. Pharm. Des. 2010, 16, 1843-1862.

20. Bleasdale, J.E.; Ogg, D.; Palazuk, B.J.; Jacob, C.S.; Swanson, M.L.; Wang, X.Y.; Thompson, D.P.; Conradi, R.A.; Mathews, W.R.; Laborde, A.L.; et al. Small molecule peptidomimetics containing a novel phosphotyrosine bioisostere inhibit protein tyrosine phosphatase 1B and augment insulin action. Biochemistry 2001, 40, 5642-5654.

21. Baykov, A.A.; Evtushenko, O.A.; Avaeva, S.M. A malachite green procedure for orthophosphate determination and its use in alkaline phosphatase-based enzyme immunoassay. Anal. Biochem. 1988, 171, 266-270.

Sample Availability: Samples of the compounds are available from the authors.

(C) 2014 by the authors; licensee MDPI, Basel, Switzerland. This article is an open access article distributed under the terms and conditions of the Creative Commons Attribution license (http://creativecommons.org/licenses/by/3.0/). 